\title{
BET Inhibitor CC-90010
}

National Cancer Institute

\section{Source}

National Cancer Institute. BET Inhibitor CC-90010. NCI Thesaurus. Code C151951.

An orally bioavailable inhibitor of the Bromodomain and Extra-Terminal (BET) family of proteins, with potential antineoplastic activity. Upon oral administration, the BET inhibitor CC-90010 preferentially binds to the second bromodomain (BD2) of BET proteins, thereby preventing the interaction between the BET proteins and acetylated histones. This disrupts chromatin remodeling and gene expression. Prevention of the expression of certain growth-promoting genes may lead to an inhibition of proliferation in BEToverexpressing tumor cells. BET proteins (BRD2, BRD3, BRD4 and BRDT) are transcriptional regulators that contain two homologous bromodomains, the BD1 and BD2 domains. They play an important role during development and cellular growth. 